\title{
Safety and efficacy of doxorubicin-eluting superabsorbent polymer microspheres for the treatment of liver metastases from neuroendocrine tumours: preliminary results
}

\author{
Lawrence Bonne ${ }^{1}$, Chris Verslype ${ }^{2}$, Annouschka Laenen ${ }^{3}$, Sandra Cornelissen ${ }^{1}$, Christophe \\ M. Deroose ${ }^{4}$, Hans Prenen², Vincent Vandecaveye ${ }^{1}$, Eric Van Cutsem², Geert Maleux ${ }^{1}$

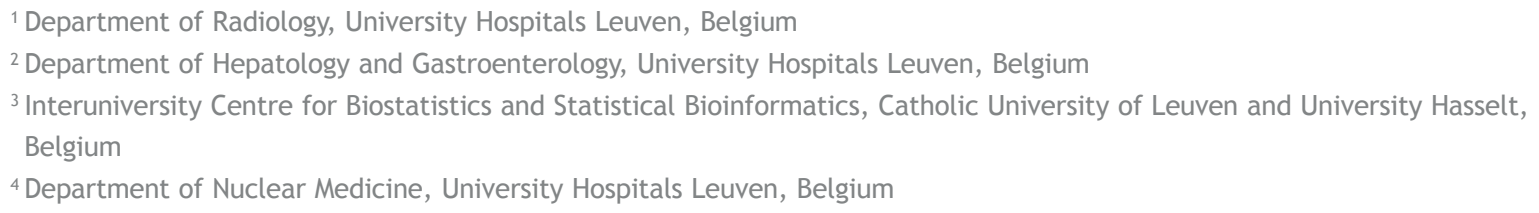

Radiol Oncol 2017; 51(1): 74-80.

Received 23 December 2016 Accepted 12 January 2017

Correspondence to: Geert Maleux, M.D., Ph.D., Department of Radiology, University Hospitals Leuven, Herestraat 49, B-3000 Leuven, Belgium. Phone: +32 163437 82; Fax: +32 163437 65; E-mail: geert.maleux@uzleuven.be

Disclosure: No potential conflicts of interest were disclosed.

Background. The aim of the study was to retrospectively evaluate the symptom control, tumour response, and complication rate in patients with liver-predominant metastatic neuroendocrine tumours treated with transarterial chemoembolization using doxorubicin-eluting superabsorbent polymer (SAP) microspheres.

Patients and methods. Patients with neuroendocrine liver metastases who underwent hepatic transarterial chemoembolization using doxorubicin-eluting SAP-microspheres (50-100 $\mu \mathrm{m}$ Hepasphere/Quadrasphere Microsphere ${ }^{\circledR}$ particles, Merit Medical, South Jordan, Utah, USA) were included in this study. Pre- and post-procedure imaging studies were evaluated to assess short and intermediate-term tumour response using modified RECIST criteria. Symptom relief and procedure-related complications were evaluated.

Results. A total of 27 embolization procedures were performed on 17 patients. Twelve of 17 patients (70\%) were symptomatic, including carcinoid syndrome $(n=8)$ and severe, uncontrollable hypoglycemia $(n=4)$. Eight of 12 patients $(67 \%)$ had complete symptom relief, and the remaining $4(33 \%)$ had partial relief. One patient developed ischemic cholecystitis (6\%). No other hepatobiliary complications occurred. Short-term and intermediate-term imaging follow-up was available for 15/17 patients (88\%) and 12/14 patients (86\%) respectively. At short-term follow-up (<3 months), 14 patients (93\%) showed partial response and the remaining patient had progressive disease (7\%). At intermediate-term imaging follow-up (> 3 months), partial response, stable disease and progressive disease were found respectively in 7 (58\%), 3 (25\%) and 2 (17\%) patients.

Conclusions. Chemoembolization with doxorubicin-eluting SAP-microspheres is a safe and effective treatment option for neuroendocrine liver metastases and is associated with a low complication rate. In particular, no clinically evident liver necrosis or bile duct complications were encountered.

Key words: neuroendocrine tumour; chemoembolization; drug-eluting beads; procedure-related complications

\section{Introduction}

Among patients with neuroendocrine tumours (NET) hepatic metastases are present in 46\%-93\% at initial presentation. ${ }^{1,2}$ The metastases may be responsible for hormone-related symptoms, including carcinoid syndrome and uncontrollable hypoglycemia in case of insulinoma. These clinical 
symptoms can be treated effectively with somatostatin analogues in more than $70 \%$ of patients, but efficacy can decrease with time. ${ }^{3}$ Although surgical resection of NET liver metastases can be $\mathrm{Cu}^{-}$ rative and remains the treatment of choice, only $10 \%$ of patients are candidates for liver surgery. ${ }^{4,5}$ Liver-directed transarterial therapies in nonsurgical candidates include transcatheter arterial embolization ${ }^{6,7}$, chemo-embolization ${ }^{6,8}$ and Yttrium-90 radioembolization. ${ }^{9,10}$ These techniques have been used both to palliate hormone-related symptoms as well as to reduce metastatic tumour burden. Conventional transarterial chemoembolization using ethiodized oil and cytotoxic drugs has been the most popular locoregional, catheter-directed therapy to treat unresectable NET liver metastases for more than 20 years. ${ }^{3,11}$ Drug-eluting microspheres have been used recently for both hepatocellular carcinoma ${ }^{12,13}$ and metastases to the liver ${ }^{14-16}$, and are associated with sustained efficacy and less systemic toxicity. ${ }^{17,18}$ In contrast to its use in hepatocellular carcinoma $^{19}$, a high complication rate was found when using drug-eluting beads (DC/LC-beads, Biocompatibles, Farnham, UK) in neuroendocrine liver metastases, including a high risk for postprocedural formation of liver necrosis and biloma. ${ }^{20-23}$

We used superabsorbent polymer (SAP) microspheres (50-100 $\mu \mathrm{m}$ Hepasphere/Quadrasphere Microspheres ${ }^{\circledR}$, Merit Medical, South Jordan, Utah, USA) loaded with doxorubicin as an alternative drug-eluting microsphere technology to treat NET liver metastases and assessed the feasibility, safety, clinical and radiological response rates in a retrospective study design.

\section{Patients and methods}

The institutional interventional radiology database was queried for patients undergoing transarterial chemoembolization using doxorubicin-eluting SAP microspheres for the treatment of liver metastases from histologically proven neuroendocrine tumours. Demographic, clinical, radiologic and laboratory data were collected. All patients were discussed at the Multidisciplinary tumour board, including medical, surgical and radiation oncologists as well as pathologists and diagnostic and interventional radiologists. All patients gave informed consent for the chemoembolization procedure and this retrospective study was approved by the local ethics committee.

Inclusion criteria for chemoembolization were symptomatic patients with liver-only or liver-pre- dominant neuroendocrine metastases, unresponsive under chemotherapy and not a candidate for surgical resection or radiofrequency ablation or patients with progression of disease, despite optimal chemotherapeutic management. Additionally, the residual liver function allowed chemoembolization: bilirubin levels less than $2.0 \mathrm{mg} / \mathrm{dl}$, alanine amino transferase (ALT) and aspartate aminotransferase (AST) less than five times the upper limit of normal, albumin more than $2 \mathrm{mg} / \mathrm{dl}$.

Contrast-enhanced computed tomography (CT) or magnetic resonance imaging (MRI) was performed within one month before the first chemoembolization procedure. Postprocedure imaging interval was variable, depending on whether a unilobar or bilobar infusion was performed within 1 session, and ranged from 1-3 months for shortterm follow-up and from 5-6 months for intermediate-term follow-up. Radiologic tumour response was assessed by size based on modified Response Evaluation Criteria in Solid Tumors (m-RECIST).

All chemoembolization procedures were performed using a standard technique as described previously for the treatment of unresectable hepatocellular carcinoma treated with doxorubicineluting SAP microspheres. ${ }^{13}$ Briefly, after administration of local anaesthesia in the right groin, a 4 French $(\mathrm{F})$ sheath (Boston Scientific, Natick, MA, USA) was introduced into the right common femoral artery. Selective catheterization of the celiac trunk and the superior mesenteric artery was performed with use of a $4 \mathrm{~F}$ catheter (Impress diagnostic catheter, Merit Medical, South Jourdan, UT, USA) and followed by superselective catheterization of the right and left hepatic arteries using a microcatheter (EmboCath Plus or Maestro 2.8, Merit Medical, South Jourdan, UT, USA). Depending on number and distribution of the metastatic lesions the drug-eluting microspheres were delivered to segmental or lobar hepatic artery/arteries. If tumour burden was more than $50 \%$ of total liver volume, 2 separate lobar infusions 1 month apart were performed. No antibiotics were administered before or during the procedure. All patients had intact biliary sphincters; analgesics or antiemetics were administered if needed. All patients received somatostatin analogues (Sandostatin, Novartis Pharma, Vilvoorde, Belgium) before the start of the procedure. For each procedure, one vial of $25 \mathrm{mg}$ dry SAP microspheres with a nominal dry diameter of 50-100 microns (Hepasphere/Quadrasphere Microspheres, Merit Medical, South Jordan, UT, USA), was prepared in the hospital pharmacy. The SAP microspheres were mixed with doxorubicin 

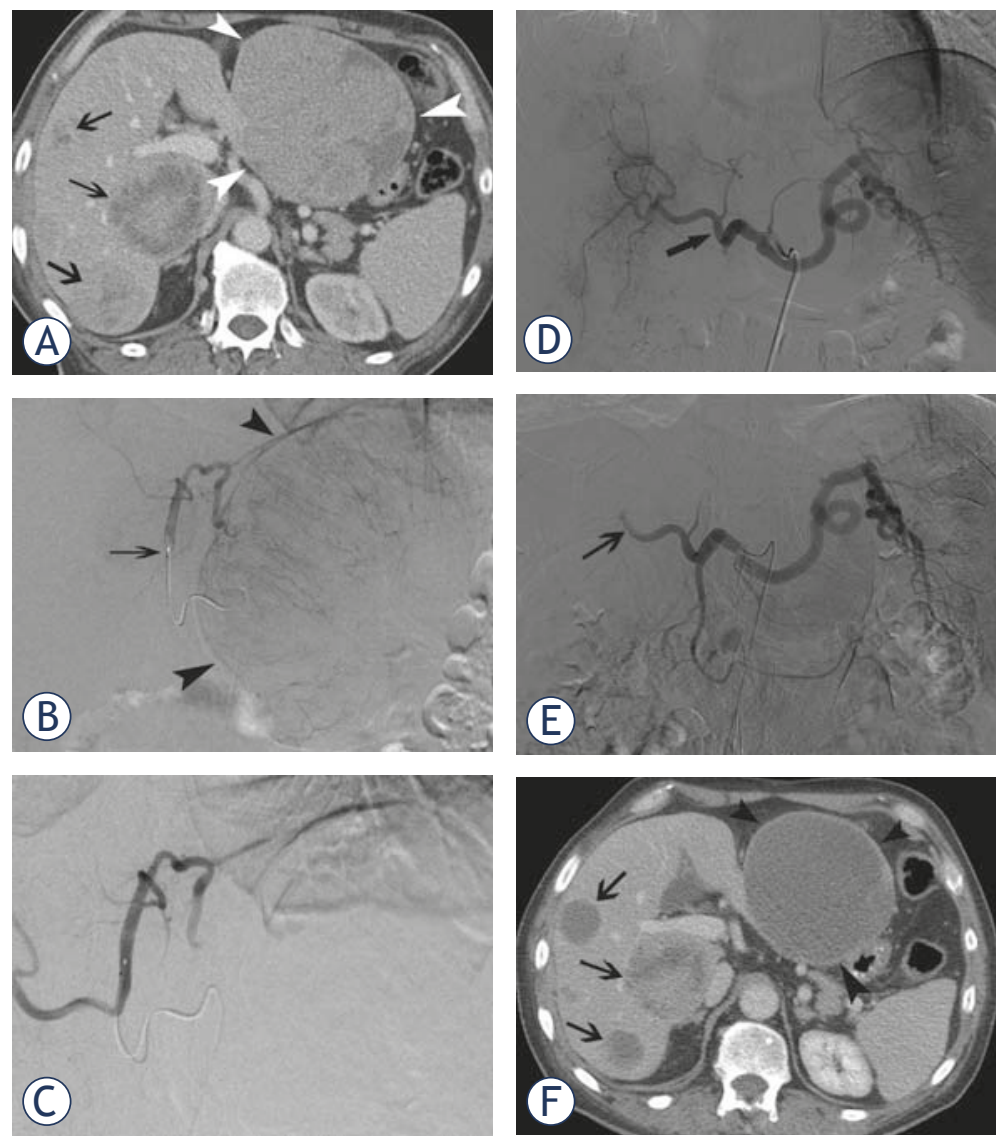

FIGURE 1. A 63-year-old male patient presented with a carcinoid of the lung and diffuse bilobar liver involvement. (A) Portal venous phase contrast-enhanced CTscan confirms diffuse metastatic involvement of both liver lobes (white arrowheads at the level of the largest metastasis in the left liver lobe; black arrows at the level of multiple smaller lesions in the right liver lobe); Selective angiogram of the left hepatic artery (B) before and (C) after chemoembolization with doxorubicin-eluting SAP-microspheres (arrow at the level of the micro-catheter in the left hepatic artery): Selective angiogram of the celiac trunk (D) before and (E) after chemoembolization with doxorubicin-eluting SAP-microspheres (arrow shows stasis of contrast at the level of the right hepatic artery); (F) Portal venous phase contrast-enhanced CT-scan 10 weeks after initial chemoembolization shows marked decrease in volume and enhancement of most of the metastatic lesions in left and right liver lobes.

(Pharmachemie BV, Haarlem, Netherlands) and suspended in $10 \mathrm{ml}$ sodium chloride $0.9 \%$ and 10 $\mathrm{ml}$ iodinated contrast medium (Visipaque 270, GE Healthcare, Oslo, Norway). The standard doxorubicin dose was $75 \mathrm{mg} / \mathrm{m}^{2}$ (square metre of body surface area), which was reduced to $50 \mathrm{mg} / \mathrm{m}^{2}$ or $25 \mathrm{mg} / \mathrm{m}^{2}$ in cases of elevated bilirubin or cytopenia. The injection of the doxorubicin-eluting SAP microspheres was stopped once the feeding arteries were completely occluded as confirmed by hand-injected hepatic angiography at completion. If residual hypervascular blush was identified on confirmation angiography after chemoemboliza- tion, an additional vial of bland polyvinyl alcohol particles (nsPVA) of 250-355 micron caliber (Contour, Boston Scientific Corporation, Natick, MA, USA) was injected.

Patients were followed clinically every 2 months on an outpatient basis; early and late adverse events were noted in the patients' electronic hospital records. Chemo-embolization-related toxicity was assessed according to the National Cancer Institute Common Terminology Criteria for Adverse Events (NCI-CTCAE) version 4.0. Assessment of symptom control after chemoembolization was performed 4-6 months after the initial chemoembolization by the referring medical oncologist. Overall survival probabilities were estimated by the Kaplan-Meier method.

\section{Results}

Seventeen patients ( 9 women, 8 men) with histologically proven gastrointestinal, pancreatic or pulmonary neuroendocrine tumours metastastic to the liver were included. Patients' age, site and type of the primary tumour, tumour grade based on the Ki-67 index, extrahepatic tumoural disease, and previous surgical and medical therapies are summarized in Table 1. No patient presented with portal vein thrombosis or bile duct dilatation at the time of chemoembolization procedure.

In 5 patients (29\%), chemoembolization of right and left liver lobes was performed in separate sessions. Both right and left liver lobes were treated in 8 patients $(47 \%)$ during the same session (Figure 1 ). For the remaining 4 patients $(24 \%)$, isolated right hepatic lobe chemoembolization was performed.

In all 27 chemoembolization procedures the whole vial of doxorubicin-loaded SAP microspheres could be injected. The total median dose of doxorubicin injected per session was $133 \mathrm{mg}$ ( $\mathrm{min}$ $25 \mathrm{mg}$ - max $150 \mathrm{mg}$ ). In 4 of 27 procedures (15\%), one additional vial of PVA particles was injected after the SAP microspheres. Procedure-related toxicity is summarized in Table 2. Management of these complications included percutaneous gallbladder drainage $(n=1)$, medical management of carcinoid and insulin storm $(n=2)$ and analgesics and antiemetics $(n=14)$. No procedure-related liver necrosis or biloma was found during immediate or late follow-up.

Short-term and intermediate-term imaging follow-up was available for $15 / 17$ patients $(88 \%)$ and $12 / 14$ patients $(86 \%)$ respectively. On short term follow-up, partial response and progressive dis- 
TABLE 1. Patients' demographic data

\begin{tabular}{|c|c|}
\hline Variable & Number \\
\hline Number of patients included & 17 \\
\hline \multicolumn{2}{|l|}{ Age (years) } \\
\hline Mean & 56 \\
\hline SD & 13.9 \\
\hline Range & $18-82$ \\
\hline \multicolumn{2}{|l|}{ Sex } \\
\hline M & 8 \\
\hline $\mathrm{F}$ & 9 \\
\hline \multicolumn{2}{|l|}{ Primary tumour } \\
\hline Intestinal NET & 6 \\
\hline Pancreatic NET & 2 \\
\hline Pulmonary NET & 2 \\
\hline Pancreatic insulinoma & 4 \\
\hline Unknown & 3 \\
\hline \multicolumn{2}{|l|}{ Surgical resection of primary tumour } \\
\hline Intestinal NET & 5 \\
\hline Pancreatic NET & 2 \\
\hline Pulmonary NET & 2 \\
\hline Pancreatic insulinoma & 1 \\
\hline Total & 10 \\
\hline \multicolumn{2}{|l|}{ Tumour grade (Ki-67 index) } \\
\hline $\mathrm{Ki}-67<2 \%$ & 4 \\
\hline Ki-67 2-20\% & 6 \\
\hline $\mathrm{Ki}-67>20 \%$ & 4 \\
\hline Unknown & 3 \\
\hline \multicolumn{2}{|l|}{ Tumour burden (\% of total liver volume) } \\
\hline $0-10 \%$ & 4 \\
\hline $10-20 \%$ & 3 \\
\hline $20-50 \%$ & 5 \\
\hline$>50 \%$ & 5 \\
\hline Extrahepatic metastatic disease & 16 \\
\hline Lymphadenopathy & 7 \\
\hline Bone & 5 \\
\hline Lung & 3 \\
\hline Spleen & 1 \\
\hline Adrenal & 3 \\
\hline Brain & 1 \\
\hline Ovary & 2 \\
\hline Pancreas & 2 \\
\hline Peritoneum & 1 \\
\hline Skin & 1 \\
\hline \multicolumn{2}{|l|}{ Previous treatment } \\
\hline Surgical resection of liver metastases & 1 \\
\hline $\begin{array}{l}\text { Radiofrequency ablation of liver } \\
\text { metastases }\end{array}$ & 1 \\
\hline Radiotherapy for brain metastases & 1 \\
\hline Radiotherapy for bone metastases & 1 \\
\hline Interferon & 3 \\
\hline Everolimus & 7 \\
\hline m-TOR-inhibitor & 1 \\
\hline Sunitinib & 4 \\
\hline Somatostatine analogue & 15 \\
\hline Diazoxide & 3 \\
\hline
\end{tabular}
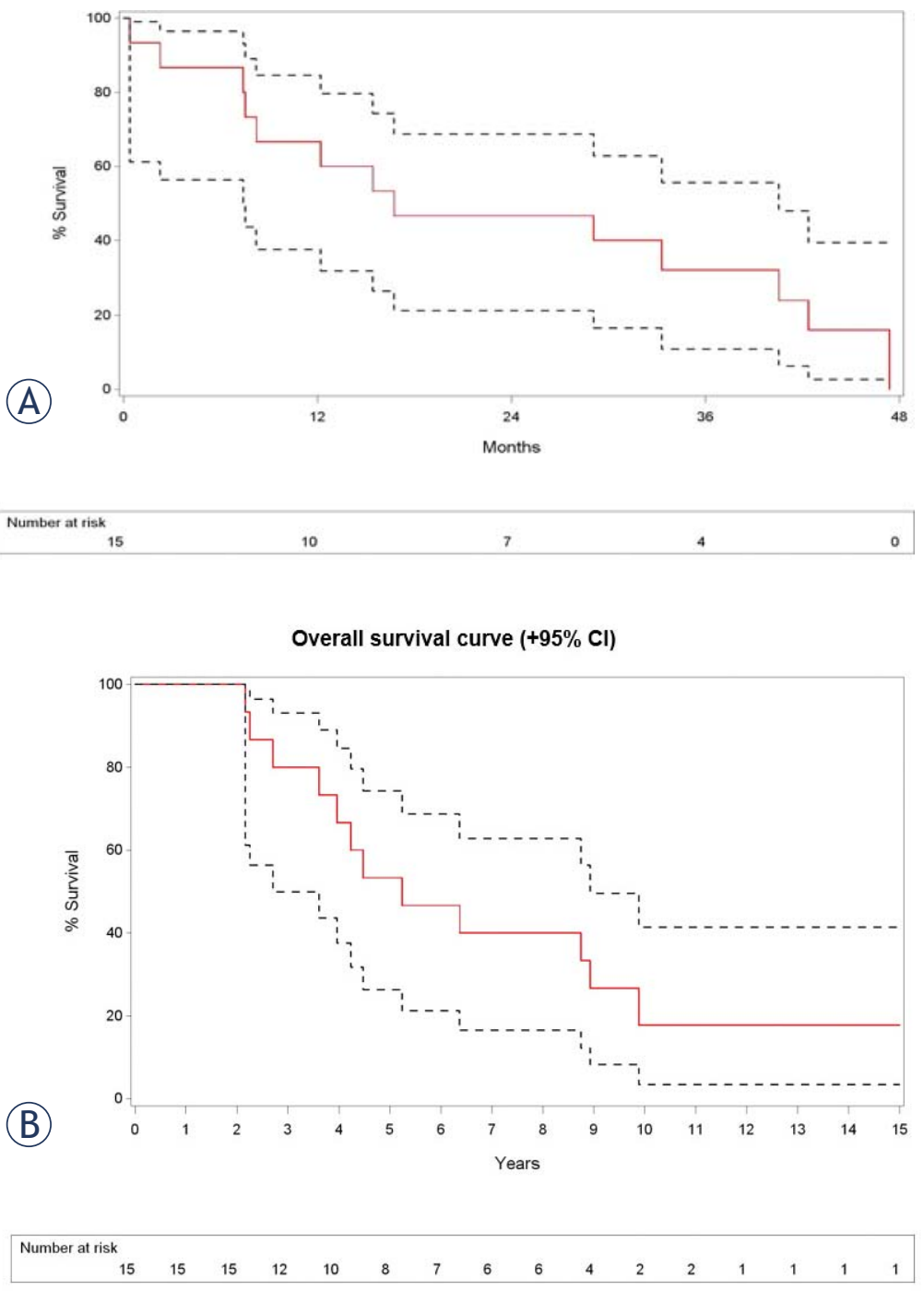

FIGURE 2. (A) Kaplan-Meier overall survival estimate shows an overall survival (with $95 \%$ confidence interval) at 12, 24 and 36 months after TACE of $67 \%$ (lower limit $38 \%$ - upper limit 85\%), $47 \%$ (lower limit $21 \%$ - upper limit 69\%) and 32\% (lower limit $11 \%$ upper limit 56\%); (B) Kaplan-Meier overall survival estimate shows an overall survival (with $95 \%$ confidence interval) at 5, 10 and 15 years after diagnosis of 53\% (lower limit 26\% - upper limit 74\%), 18\% (lower limit 3\% - upper limit 41\%) and 18\% (lower limit $3 \%$ - upper limit $41 \%)$.

ease according to m-RECIST criteria were found in $14(93 \%)$ and $1(7 \%)$ patients respectively. On intermediate term follow-up, m-RECIST-based partial response, stable disease and progressive disease was found respectively in $7(58 \%), 3(25 \%)$ and 2 $(17 \%)$ patients.

Eight of 17 patients $(47 \%)$ presented with carcinoid syndrome-related symptoms including diarrhea $(\mathrm{n}=7 ; 41 \%)$ and flushing $(\mathrm{n}=7 ; 41 \%) ; 5$ of these 8 patients $(63 \%)$ had complete symptom relief after chemoembolization. The remaining 3 pa- 
TABLE 2. Procedure-related toxicity

\begin{tabular}{lccc}
\hline Toxicity & grade & $\begin{array}{c}\text { number of } \\
\text { patients }\end{array}$ & $\begin{array}{c}\text { percentage } \\
\text { (\%) }\end{array}$ \\
\hline Ischemic cholecystits & 3 & 1 & 6 \\
Carcinoid storm & 2 & 1 & 6 \\
$\begin{array}{l}\text { Insulin storm } \\
\begin{array}{l}\text { Postembolization } \\
\text { syndrome }\end{array}\end{array}$ & 2 & 1 & 6 \\
\hline
\end{tabular}

Grading of procedure-related toxicity is based on National Cancer Institute - Common Terminology Criteria for Adverse Events (NCI-CTCAE) version 4.0.

tients had moderate relief of symptoms with persisting signs of diarrhea $(\mathrm{n}=2)$ and flushing $(\mathrm{n}=$ 3). Three of 4 patients with liver metastases related to primary insulinoma of the pancreas (pre-interventional mean glycemia values of $57 \mathrm{mg} / \mathrm{dl}$ (range $39-83 \mathrm{mg} / \mathrm{dl})$ ) had complete normalisation of their glycaemic values after the chemoembolization procedure. One patient had a partial clinical response with a residual glycemic value of $100 \mathrm{mg} / \mathrm{dl}$. One patient with predominant symptoms of abdominal pain did not respond to the chemoembolization treatment. Overall survival of the studied patients is summarized in Figure 2 with an estimated survival at one year after TACE of $67 \%$, and an estimated survival at five years after diagnosis of $53 \%$.

\section{Discussion}

This retrospective observational study shows a high rate of symptomatic relief after chemoembolization for neuroendocrine liver metastases using doxorubicin-eluting SAP-microspheres: 5 of 8 patients with carcinoid syndrome-related symptoms showed complete symptom relief after the first session of chemoembolization and 3 of 4 patients with preinterventional hypoglycemia presented with complete normalisation of their glycemic values. These results are consistent with symptomatic responses after conventional chemoembolization showing symptom relief in $52 \%-86 \%$ of cases. These encouraging results are even higher when the treatment is performed as a first line therapy, with up to $70 \%$ complete symptomatic response and $20 \%$ partial response. $3,6,8,11$

This study also demonstrates substantial radiologic response rates, with $93 \%$ of patients showing partial response or stable disease at 3 month follow-up, based on modified RECIST criteria. These results are consistent with response rates using doxorubicin-eluting DC Beads (BTGBiocompatibles, Farnham, UK) or using conventional ethiodized oil-based chemoembolization, which range between $57 \%$ and $80 \%{ }^{8,20,21}$ These high response rates potentially can also be achieved in patients with high tumour burden, as suggested in the present study, with tumour burden ranging from $8 \%$ to $58 \%$. Bland embolization without the addition of any chemotherapeutic agent also has demonstrated high response rates similar to those of chemoembolization. ${ }^{3,6,11}$ Although most of the studies dealing with catheter-directed liver interventions for neuroendocrine metastases are based on chemo-embolization, however, no retro- or prospective comparative study has demonstrated a significant difference in response rate or other benefit for chemoembolization compared to bland embolization.

Toxicity related to SAP microsphere-based chemoembolization for neuroendocrine liver metastases is mainly limited to the post-embolization syndrome which was observed in $82 \%$ of cases. Only one case of post-embolization cholecystitis was observed, which was treated by percutaneous drainage, and one instance each of post-embolization carcinoid $(n=1)$ and insulin $(n=1)$ storm occurred despite prophylactic administration of somatostatin analogues before chemoembolization. Importantly, we did not observe any cases of postembolization liver necrosis, liver abscess or biloma. Post-chemoembolization liver abscess formation is a risk in patients with biliodigestive anastomosis or biliary stents in situ, despite the prophylactic administration of broad spectrum antibiotics. ${ }^{8,24}$ In this series there were no patients with previous bile duct surgery or intervention. In other studies post-embolization liver necrosis and intrahepatic biloma-formation were found in nearly half of the cases using small calibre $(100-300 \mu \mathrm{m})$ doxorubicin-loaded DC Beads, but not after conventional, ethiodized oil-based chemoembolization. ${ }^{20-22,25}$ It is unclear why this high number of biloma cases was found after DC/LC Bead chemoembolization for neuroendocrine liver metastases; it is hypothesized that small calibre microspheres will penetrate deeper in the (normal) residual liver parenchyma and thereby induce irreversible ischemia to the liver and biliary tree tissues. ${ }^{20}$ This serious side effect was seen more often in patients with a smaller tumour burden compared to patients with a higher tumour load, stressing the fact that the residual normal liver parenchyma is sensible to ischemic changes when small calibre microspheres are injected. ${ }^{20}$ SAP microspheres used in this study had 
a diameter of $50-100 \mu \mathrm{m}$ in their dry state, swelling to $200-400 \mu \mathrm{m}$ once hydrated in saline solution. This mechanism of expansion and subsequent larger diameter, thereby resulting in a more proximal embolization when injected into the liver ${ }^{26-28}$, might prevent any necrotic complication.

Finally, we did not observe procedure-related liver failure, even in patients with considerable tumour burden, bilobar treatment, or in patients heavily pretreated by somatostatin analogues and different types of other drugs.

Limitations of this study are multiple. First, this study deals with a very heterogeneous patient population presenting with both symptomatic and asymptomatic neuroendocrine liver metastases who were previously treated with various types of chemotherapeutics and other medical treatments. Second, the patient sample is too small to draw firm conclusions with regard to symptom and tumour responses. Third, late response rates as well as overall survival also depend on prior, concomitant and further treatment options and not on the chemoembolization procedures alone. Last, no comparative analysis with other locoregional or medical treatments was performed.

In conclusion, this study suggests that doxorubicin-eluting SAP microspheres appear to be a safe and potentially effective treatment option in the treatment of neuroendocrine liver metastases and this interventional technique might be proposed as an alternative locoregional treatment option for conventional ethiodized oil-based chemoembolization.

\section{References}

1. Chamberlain R, Canes D, Brown K, Saltz L, Jarnagin W, Fong $Y$, et al. Hepatic neuroendocrine metastases: does intervention alter outcome? J Am Coll Surg 2000; 190: 432-45. doi: http://dx.doi.org/10.1016/S10727515(00)00222-2

2. Tomassetti P, Migliori M, Lalli S, Campana D, Tomassetti V, Corinaldesi R. Epidemiology, clinical features and diagnosis of gastroenteropancreatic endocrine tumors. Ann Oncol 2001; 12 (Suppl 2): S95-9.

3. Madoff D, Gupta S, Ahrar K, Murthy R, Yao JC. Update on the management of neuroendocrine hepatic metastases. J Vasc Interv Radiol 2006; 17: 1235 49; quiz 1250. doi: 10.1097/01.RVI.0000232177.57950.71

4. Mayo S, De Jong M, Bloomston M, Pulitano C, Clary B, Reddy S, et al. Surgery versus intra-arterial therapy for neuroendocrine liver metastases: a multicenter international analysis. Ann Surg Oncol 2011; 18: 3657-65. doi: 10.1245/s10434-010-1343-2

5. Arrese D, McNally ME, Chokshi R, Feria-Arias E, Schmidt C, Klemanski D, et al. Extrahepatic disease should not preclude transarterial chemoembolization for metastatic neuroendocrine carcinoma. Ann Surg Oncol 2013; 20: 1114-20. doi: 10.1245/s10434-012-2786-4

6. Ruutiainen A, Soulen M, Tuite C, Clark T, Mondschein J, Stavropoulos S, et al. Chemoembolization and bland embolization of neuroendocrine tumor metastases to the liver. J Vasc Interv Radiol 2007; 18: 847-55. doi: 10.1016/j. jvir.2007.04.018
7. Ho A, Picus J, Darcy MD, Tan B, Gould JE, Pilgram TK, et al. Long-term outcome after chemoembolization and embolization of hepatic metastatic lesions from neuroendocrine tumors. AJR Am J Roentgenol 2007; 188: 12017. doi: $10.2214 /$ AJR.06.0933

8. Hur S, Chung J, Kim H, Oh D, Lee S, Bang Y, et al. Survival outcomes and prognostic factors of transcatheter arterial chemoembolization for hepatic neuroendocrine metastases. J Vasc Interv Radiol 2013; 24: 947-56. doi: 10.1016/j.jvir.2013.02.030

9. Devcic Z, Rosenberg J, Braat A, Techasith T, Banerjee A, Sze D, et al. The efficacy of hepatic $90 Y$ resin radioembolization for metastastic neuroendocrine tumors: a meta-analysis. J Nuc Med 2014; 55: 1404-10. doi: 10.2967/ jnumed.113.135855

10. Memon K, Lewandowski R, Mulcahy M, Riaz A, Ryu R, Sato K, et al. Radioembolization for neuroendocrine liver metastases: safety, imaging and long-term outcomes. Int J Radiat Oncol Biol Phys 2012; 83: 887-94. doi: 10.1016/j.ijrobp.2011.07.041

11. de Baere T, Deschamps F, Tselikas L, Ducreux M, Planchard D, Pearson E, et al. GEP-NETS update: Interventional radiology: role in the treatment of liver metastases from GEP-NETs. Eur J Endocrinol 2015; 172: R151-66. doi: 10.1530/EJE-14-0630

12. Lammer J, Malagari K, Vogl T, Pilleul F, Denys A, Watkinson A, et al; PRECISION V Investigators. Prospective randomized study of doxorubicineluting-bead embolization in the treatment of hepatocellular carcinoma: results of the PRECISION study. Cardiovasc Intervent Radiol 2010; 33: 41-45. doi: 10.1007/s00270-009-9711-7

13. Dekervel J, van Malenstein H, Vandecaveye V, Nevens F, van Pelt J, Heye S, et al. Transcatheter arterial chemoembolization with doxorubicin-eluting superabsorbent polymer microspheres in the treatment of hepatocellular carcinoma: midterm follow-up. J Vasc Interv Radiol 2014; 25: 248-55. doi: 10.1016/j.jvir.2013.10.017

14. Huppert $\mathrm{P}$, Wenzel $\mathrm{T}$, Wietholtz $\mathrm{H}$. Transcatheter arterial chemoembolization (TACE) of colorectal cancer liver metastases by irinotecan-eluting microspheres in a salvage patient population. Cardiovasc Intervent Radiol 2014; 37: 154-64. doi:10.1007/s00270-013-0632-0

15. Aliberti C, Fiorentini G, Muzzio PC, Pomerri F, Tilli M, Dallara S, et al. Transarterial chemoembolization of metastatic colorectal carcinoma to the liver adopting DC Bead ${ }^{\circledR}$, drug-eluting bead loaded with irinotecan: results of a phase II clinical study. Anticancer Res 2011; 31: 4581-7.

16. Fiorentini G, Aliberti C, Turrisi G, Del Conte A, Rossi S, Benea G, et al. Intraarterial hepatic chemoembolization of liver metastases from colorectal cancer adopting irinotecan-eluting beads: results of a phase II clinical study. In Vivo 2007; 21: 1085-91.

17. van Malenstein $H$, Maleux $G$, Vandecaveye $V$, Heye $S$, Laleman $W$, van Pelt J, et al. A randomized phase II study of drug-eluting beads versus transarterial chemoembolization for unresectable hepatocellular carcinoma. Onkologie 2011; 34: 368-76. doi: 10.1159/000329602.

18. Varela $M$, Real $M$, Burrel $M$, Forner $A$, Sala $M$, Brunet $M$, et al. Chemoembolization of hepatocellular carcinoma with drug eluting beads: efficacy and doxorubicin pharmacokinetics. J Hepatol 2007; 46: 474-81. doi: 10.1016/j.jhep.2006.10.020

19. Vogl T, Lammer J, Lencioni R, Malagari K, Watkinson A, Pilleul F, et al. Liver, gastrointestinal and cardiac toxicity in intermediate hepatocellular carcinoma with PRECISION TACE with drug-eluting beads: results from the PRECISION V randomized trial. AJR Am J Roentgenol 2011; 197: W562-70. doi: 10.2214/AJR.10.4379

20. Bhagat N, Reyes D, Lin M, Kamel I, Pawlik T, Frangakis C, et al. Phase II study of chemoembolization with drug-eluting beads in patients with hepatic neuroendocrine metastases: high incidence of biliary injury. Cardiovasc Intervent Radio/ 2013: 36: 449-59. doi: 10.1016/j.jvir.2012.08.028

21. Guiu B, Descamps F, Aho S, Munck F, Dromain C, Boige V, et al. Liver/biliary injuries following chemoembolization of endocrine tumours and hepatocellular carcinoma: lipiodol versus drug-eluting beads. J Hepatol 2012: 56: 609-617. doi: 10.1016/j.jhep.2011.09.012

22. Joskin J, de Baere T, Auperin A, Tselikas L, Guiu B, Farouil G, et al. Predisposing factors of liver necrosis after transcatheter arterial chemoembolization in liver metastases from neuroendocrine tumor. Cardiovasc Intervent Radiol 2015; 38: 372-380. doi: 10.1016/j.jhep.2011.09.012 
23. De Baere T, Deschamps F, Teriitheau C, Rao P, Conengrapht K, Schlumberger $\mathrm{M}$, et al. Transarterial chemoembolization of liver metastases from well differentiated gastroenteropancreatic endocrine tumors with doxorubicineluting beads: preliminary results. J Vasc Interv Radiol 2008; 19: 855-61. doi: 10.1016/j.jvir.2008.01.030

24. Sakamoto I, Iwanaga S, Nagaoki K, Matsuoka Y, Ashizawa K, Uetani M, et al. Intrahepatic biloma formation (bile duct necrosis) after transcatheter arterial chemoembolization. AJR Am J Roentgenol 2003; 181: 79-87. doi: 10.2214/ajr.181.1.1810079

25. Gaur S, Friese J, Sadow C, Ayyagari R, Binkert C, Schenker M, et al. Hepatic arterial chemoembolization using drug-eluting beads in gastrointestinal neuroendocrine tumor metastatic to the liver. Cardiovasc Intervent Radiol 2011; 34: 566-72. doi: 10.1007/s00270-011-0122-1

26. Loewe C, Schindl M, Cejna M, Niederle B, Lammer J, Thurnher S. Permanent transarterial embolization of neuroendocrine metastases of th eliver using cyanoacrylate and lipiodol: assessment of mid- and long-term results. AJR Am J Roentgenol 2003; 180: 1379-84. doi: 10.2214/ajr.180.5.1801379

27. Bilbao J, de Luis E, García de Jalón JA, de Martino A, Lozano MD, de la Cuesta AM, et al. Comparative study of four different spherical embolic particles in an animal model: a morphologic and histologic evaluation. J Vasc Interv Radiol 2008; 19: 1625-38. doi: 10.1016/j.jvir.2008.07.014

28. De Luis E, Bilbao JI, de Ciércoles JA, Martínez-Cuesta A, de Martino Rodríguez A, Lozano MD. In vivo evaluation of a new embolic spherical particle (HepaSphere) in a kidney animal model. Cardiovasc Intervent Radio 2008; 31: 367-76. doi: 10.1007/s00270-007-9240-1 